\title{
Fatty acid composition of beef steers as affected by diet and fat depot
}

\author{
C. Mapiye ${ }^{1}$, P. Vahmani' ${ }^{2}$ J.L. Aalhus ${ }^{2}$, D.C. Rolland ${ }^{2}$, V.S. Baron ${ }^{2}$, T.A. McAllister ${ }^{3}$, \\ H.C. Block ${ }^{2}$, B. Uttaro ${ }^{2}$ \& M.E.R. Dugan ${ }^{2 \#}$ \\ ${ }^{1}$ Department of Animal Sciences, Faculty of AgriSciences, Stellenbosch University, P. Bag X1, Matieland 7602, South \\ Africa ${ }^{2}$ Agriculture and Agri-Food Canada (AAFC), Lacombe Research Centre, $6000 \mathrm{C} \& \mathrm{E}$ Trail, Lacombe, Alberta, \\ Canada T4L 1W1, ${ }^{3}$ AAFC, Lethbridge Research Centre, $1^{\text {st }}$ Avenue South 5403, PO Box 3000, Lethbridge, Alberta, \\ Canada T1J 4B1
}

(Received 3 February 2015; Accepted 3 August 2015; First published online 9 October 2015)

Copyright resides with the authors in terms of the Creative Commons Attribution 2.5 South African Licence.
See: http://creativecommons.org/licenses/by/2.5/za
Condition of use: The user may copy, distribute, transmit and adapt the work, but must recognise the authors and the South African
Journal of Animal Science.

\begin{abstract}
Subcutaneous and perirenal fatty acid (FA) profiles were compared in steers fed a control diet $(70: 30$ red clover silage (RC) : barley concentrate), a diet with sunflower seed (SS) substituted for barley, and diets with $15 \%$ or $30 \%$ wheat dried distillers' grain with solubles (DDGS-15 and DDGS-30) substituted for RC and SS. Perirenal fat (PRF) versus subcutaneous fat (SCF) had greater proportions of total saturated FA (SFA) and branched chain FA (BCFA), and lower proportions of total and major cis-monounsaturated FA (C-MUFA). Addition of SS to the diet did not change the proportions of total and major $c$-MUFA and $n-6$ polyunsaturated FA (PUFA), but led to decreases in the proportions of total and major SFA, BCFA and $n-3$ PUFA. Progressive substitutions with DDGS led to no further changes in the proportions of total and major SFA and $n-3$ PUFA, but decreased the proportions of BCFA and $c 9-16: 1$, and increased the proportions of $c 9-18: 1$ and $n-6$ PUFA. Feeding SS and DDGS-15 diets yielded the largest proportions of total and major $t-18: 1$ (t11and $t 13-/ t 14-18: 1)$ isomers in PRF and conjugated lineolic acid (CLA) isomers (t7,c9- and t9,c11-18:2) in SCF, but responses were diminished when feeding the DDGS-30 diet. Subcutaneous fat versus PRF from steers fed SS and DGGS diets had larger proportions of non-conjugated 18:2 biohydrogenation products (i.e. atypical dienes) than the control diet. Overall, feeding SS and DDGS-15 diets raised the proportions of $t 11$ 18:1 in PRF and c9,t11-18:2 in SCF, which have potential human health benefits, but feeding DDGS-30 was less effective.
\end{abstract}

Keywords: Beef, rumenic acid, vaccenic acid

\#Corresponding author: duganm@agr.gc.ca

\section{Introduction}

In the past two decades, links between intake of trans fatty acids (FA) and saturated FA with heart disease have led to recommendations to limit their consumption in foods, including beef (Mapiye et al., 2015; Nantapo et al., 2015; Vahmani et al., 2015). Recently, growing consumer interest in healthy diets has triggered research to enrich beef with polyunsaturated fatty acids (PUFA) and biohydrogenation products (BHP), particularly rumenic acid (cis 9, trans 11-18:2) and its precursor vaccenic acid (trans 11-18:1; Mapiye et al., 2012; 2015) which have potential human health benefits (Field et al., 2009; Dilzer et al., 2012). The proportions of these BHP in beef can be increased by feeding forages in combination with high levels of PUFA (Mapiye et al., 2012; 2015; Vahmani et al., 2015). However, feeding PUFA in high-forage diets results in lower growth rates, smaller carcasses and an undesirable meat appearance compared with high concentrate diets (Webb, 2006; Mapiye et al., 2013a). Recently, it was demonstrated that these problems could in part be alleviated by replacing forage (red clover silage (RC)) with wheat dried distillers' grains plus solubles (DDGS) as a non-forage fibre source (Mapiye et al., 2014a).

The composition of PUFA-BHP in beef is influenced by fat depot, with external depots (e.g. subcutaneous fat (SCF)) and internal depots (e.g. perineal fat (PRF)) with the greatest propensity to accumulate rumenic and vaccenic acids, respectively (Jiang et al., 2013; Mapiye et al., 2013b; 2014b). These differences have important health implications when one examines which depot could be incorporated into meat products such as minced beef. Currently, SCF is used when making minced beef, which is considered by many to be the most popular and most versatile of all beef products (Brewer, 2012). On the other hand, PRF is an underutilized fat depot, but has a higher content of total PUFA-BHP and is more easily accessible during the slaughter process than SCF (Mapiye et al., 2014b). Strategies to enhance the PUFA- 
BHP composition of beef products should therefore include feeding designer diets and exploiting fat depot heterogeneity. The current study was an extension of the research by Mapiye et al. (2014a). The objective was to compare PUFA-BHP profiles in SCF and PRF fat from the same group of steers fed RC sunflower seed and varying levels of wheat dried distillers' grain with solubles (DDGS).

\section{Material and Methods}

Animal management and the ingredients and nutritional composition of experimental diets were previously described by Mapiye et al. (2014a). Briefly, sixty-four 12-month-old British $\times$ Continental crossbred steers with an initial mean bodyweight $(\mathrm{BW})$ of $362.7 \pm 4.50 \mathrm{~kg}$ were randomly allocated to four dietary treatments (control, sunflower seed (SS), DDGS-15 and DDGS-30), with two pens of eight steers per dietary treatment. The control diet was composed of $70 \%$ red clover silage, $25.8 \%$ barley grain and $4.2 \%$ vitaminmineral supplement on a dry matter (DM) basis (Table 1). The SS diet contained $11.4 \%$ SS substituted for barley grain, and the DDGS-15 and DDGS-30 diets contained 15\% and 30\% DDGS, respectively, substituted for red clover silage and SS to maintain a targeted $5 \%$ added oil in the diets from SS or DDGS (Table 1).

At slaughter, PRF was collected closest to the geometric centre of the whole PRF, vacuum packed and held in a $2^{\circ} \mathrm{C}$ cooler with a wind speed of $0.5 \mathrm{~m} / \mathrm{sec}$ pending FA analysis. Carcasses were cooled for 24 $\mathrm{h}$ under the same conditions prior to collecting and vacuum packing SCF covering the longissimus thoracis et lumborum. A $50 \mathrm{~g}$ subsample of each fat depot was homogenized using a Robot Coupe Blixir BX3 food processor (Robot Coupe USA Inc., Ridgeland, Miss, USA) and frozen at $-80^{\circ} \mathrm{C}$ for subsequent FA analysis.

For FA analysis, $50 \mathrm{mg}$ fat was freeze dried and directly methylated with $0.5 \mathrm{M}$ sodium methoxide (Aldai et al., 2009). Fatty acid methyl esters were analysed by gas chromatography (GC) using a CP-Sil88 column (100 m, $25 \mu \mathrm{m}$ ID, $0.2 \mu \mathrm{m}$ film thickness) in a CP-3800 gas chromatograph equipped with an 8600series autosampler (Varian Inc., Walnut Creek, Calif, USA). Two GC analyses were conducted per sample using complementary temperature programmes with $150^{\circ} \mathrm{C}$ and $175^{\circ} \mathrm{C}$ plateaus according to Kramer et al. (2008). Conjugated linoleic acid (CLA) isomers not separated by GC were further analysed using $\mathrm{Ag}^{+}-\mathrm{HPLC}$ as described by Cruz-Hernandez et al. (2004). Individual peaks were identified with reference standards (GLC-603, Nu-Chek Prep. Inc., Elysian, Minn, USA; BC-Mix1, Applied Science, State College, Pa, USA) and peak orders and retention times reported in the literature (Cruz-Hernandez et al., 2004; Kramer et al., 2008; Gómez-Cortés et al., 2009).

Statistical analyses were conducted using Proc Mixed of statistical analytical systems (SAS, 2009). All the data were analysed as a two-way ANOVA, including fixed effects of diet, fat depot and diet $\times$ fat depot interaction, and slaughter day and animal (diet) as random effects. Treatment means were generated and separated using the LSMEANS and PDIFF options, respectively. The significance threshold was set at $P$ $<0.05$.

\section{Results and Discussion \\ Fatty acids of dietary or endogenous origin}

Diet and its interaction with fat depot did not $(P>0.05)$ affect total FA content (Table 2). Overall, the proportions of total saturated FA (SFA), 14:0 and 16:0 decreased $(P<0.05)$ with SS addition, but further substitutions with DDGS led to no further changes $(P>0.05$; Table 2$)$. Conversely, the proportions of 18:0 increased $(P<0.05)$ with the addition of SS to the control diet, but further substitutions with DDGS led to no $(P>0.05)$ further changes. These results resemble patterns of dietary proportions of the individual SFA observed in the current study. Current results may also be partly linked to the influences of both rates of complete biohydrogenation of PUFA to $18: 0$ and high proportions of 18:2n-6, which were previously reported by Shingfield et al. (2013) to down-regulate $\Delta-9$ desaturase activity in adipose tissues.

The proportions of total cis-monounsaturated FA (c-MUFA) were not $(P>0.05)$ influenced by diet. The proportions of $c 9-14: 1$ tended to decline $(P=0.06)$ with the addition of SS to the control diet. The inclusion of DDGS led to further reductions $(P=0.06)$. Shingfield et al. (2013) reported similar results and attributed them to the inhibitory effects of high dietary levels of $18: 2 n-6$ on de novo synthesis of $F A$, including conversion of 14:0 to $c 9-14: 1$. Adding SS to the control diet did not $(P>0.05)$ change the proportions of $c 9$ 16:1 (Table 2), but further substitutions with DDGS did reduce $(P<0.05)$ its proportions. The results could be linked partly to the high proportions of $18: 2 n-6$ in adipose tissues that were observed when feeding DDGS diets (Table 2).

According to Nakamura et al. (2004), high levels of $18: 2 n-6$ can inhibit $\Delta-9$ desaturase activity, consequently reducing de novo synthesis of $c 9-16: 1$ from 16:0. Feeding SS diet had no $(P>0.05)$ effect on the proportions of $c 9-18: 1$, but further substitutions with DDGS increased $(P<0.05)$ its proportions (Table 2). In line with current findings, Cruz-Hernandez et al. (2007) demonstrated that increasing 18:2n-6 in the diet is capable of inhibiting biohydrogenation in the rumen, leading to the accumulation of intermediate products in 
adipose tissues. Overall, variations in c-MUFA are difficult to interpret, because $c$-MUFA can originate from both diet and endogenous synthesis.

Table 1 Ingredients, nutrients and fatty acid composition of the dietary treatments

\begin{tabular}{|c|c|c|c|c|c|}
\hline \multirow{2}{*}{ Variable } & \multicolumn{4}{|c|}{ Dietary treatments } & \multirow[b]{2}{*}{ SD } \\
\hline & Control & sS & DDGS-15 & DDGS-30 & \\
\hline \multicolumn{6}{|l|}{ Ingredients (\% DM basis) } \\
\hline Sunflower-seed & 0.0 & 11.4 & 9.2 & 7.0 & $\mathrm{~N} / \mathrm{A}$ \\
\hline Dried distiller' grains with solubles & 0.0 & 0.0 & 15.0 & 30.0 & $N / A$ \\
\hline Barley grain & 25.8 & 14.4 & 14.4 & 14.4 & $\mathrm{~N} / \mathrm{A}$ \\
\hline Red clover & 70.0 & 70.0 & 57.2 & 44.4 & $\mathrm{~N} / \mathrm{A}$ \\
\hline Vitamin/mineral supplement ${ }^{1}$ & 4.2 & 4.2 & 4.2 & 4.2 & $N / A$ \\
\hline \multicolumn{6}{|l|}{ Nutrient composition (g/kg DM) } \\
\hline Dry matter & 426 & 402 & 442 & 501 & 42 \\
\hline Crude protein & 131 & 134 & 165 & 208 & 36 \\
\hline Crude fat & 18.9 & 64.0 & 58.0 & 59.0 & 20.9 \\
\hline Calcium & 8.6 & 9.2 & 8.1 & 6.9 & 1.0 \\
\hline Phosphorus & 3.1 & 3.2 & 4.1 & 5.3 & 1 \\
\hline Acid detergent fibre & 337 & 370 & 338 & 284 & 36 \\
\hline Neutral detergent fibre & 433 & 487 & 445 & 385 & 42 \\
\hline Digestible energy (MJ/kg) & 11.3 & 10.8 & 11.4 & 12.2 & 0.59 \\
\hline \multicolumn{6}{|l|}{ Fatty acids (\% of total fatty acids) } \\
\hline $14: 0$ & 0.35 & 0.17 & 0.15 & 0.15 & 0.10 \\
\hline $16: 0$ & 18.8 & 10.6 & 11.9 & 13.5 & 3.60 \\
\hline 18:0 & 2.86 & 4.15 & 3.67 & 3.24 & 0.56 \\
\hline $20: 0$ & 1.11 & 0.65 & 0.49 & 0.41 & 0.31 \\
\hline $22: 0$ & 1.29 & 1.11 & 0.85 & 0.71 & 0.26 \\
\hline $24: 0$ & 1.25 & 0.70 & 0.52 & 0.44 & 0.36 \\
\hline c9-18:1 & 9.49 & 12.4 & 13.0 & 13.3 & 1.75 \\
\hline c11-18:1 & 0.93 & 0.73 & 0.76 & 0.78 & 0.09 \\
\hline $18: 3 n-3$ & 18.9 & 7.09 & 6.26 & 5.59 & 6.32 \\
\hline $18: 2 n-6$ & 39.0 & 59.6 & 60.3 & 60.1 & 10.5 \\
\hline
\end{tabular}

SS: sunflower seed; DDGS-15: 15\% wheat dried distillers' grain with solubles + sunflower seed; DDGS-30: $30 \%$ wheat dried distillers' grain with solubles + sunflower seed; SD: standard deviation; N/A: not applicable.

${ }_{1}$ Vitamin/mineral supplement per $\mathrm{kg}$ DM contained $18.6 \mathrm{~g}$ calcium; $9.3 \mathrm{~g}$ phosphorus; $5.6 \mathrm{~g}$ potassium; $2.1 \mathrm{~g}$ sulphur; $3.3 \mathrm{~g}$ magnesium; $9.2 \mathrm{~g}$ sodium; $265 \mathrm{mg}$ iron; $314 \mathrm{mg}$ manganese; $156 \mathrm{mg}$ copper; $517 \mathrm{mg}$ zinc; $10.05 \mathrm{mg}$ iodine; $5.04 \mathrm{mg}$ cobalt; $2.98 \mathrm{mg}$ selenium; 49722 IU vitamin A; 9944 IU vitamin $\mathrm{D}_{3} ; 3222$ IU vitamin $\mathrm{E}$.

Inclusion of SS in the control diet led to reductions $(P<0.05)$ in the proportions of total and major $n-3$ PUFA, but further substitutions with DDGS led to no $(P>0.05)$ further changes (Table 2$)$. This is consistent with the dietary proportions of 18:3n-3 for the various dietary treatments. Thus, these results could be related to the substitution of barley grain and RC with SS and DDGS, which both have relatively lower concentrations of $18: 3 n-3$. There is also a possibility that high proportions of $18: 2 n-6$ in the adipose tissues of steers fed SS and DDGS might have reduced the elongation of 18:3n-3 to $22: 5 n-3$ due to competition for the $\Delta-6$ desaturase (Johnson et al., 2012).

Overall, feeding SS had no effect $(P>0.05)$ on total and major $n-6$ PUFA, but feeding increasing levels of DDGS raised $(P<0.05)$ the proportions of these FAs (Table 2$)$. The proportions of total PUFA declined $(P$ 
$<0.05)$ when feeding SS, and increased $(P<0.05)$ when feeding increasing levels of DDGS (Table 2). These findings may be explained by a combination of dietary fibre, 18:2n-6 and DM intake reported for the various diets in the current study by Mapiye et al. (2014a). The $n-6: n-3$ ratio increased $(P<0.05)$ with the addition of SS in the control diet. These proportions were accentuated by inclusion of DDGS (Table 2). Overall, including $n$-6 PUFA sources in the diet of the animal increases the proportions of $n-6$ PUFA in the tissues, due mostly to concomitant decreases in the proportions of $n$-3 PUFA, and this subsequently increases the $n-6: n-3$ ratio (Raes et al., 2004). For PUFA : SFA, the DDGS-30 diet had a greater $(P<0.05)$ ratio than other diets (Table 2) which was associated with higher PUFA and lower SFA reported for this diet.

Table 2 Effect of diet on adipose tissue fatty acids (\% total FA) of endogenous or dietary origin from beef steers

\begin{tabular}{|c|c|c|c|c|c|c|}
\hline & \multicolumn{4}{|c|}{ Diet } & \multirow{2}{*}{ SEM } & \multirow{2}{*}{$P$-value } \\
\hline & Control & ss & DDGS-15 & DGGS-30 & & \\
\hline$\sum \mathrm{FA}(\mathrm{mg} / \mathrm{g})$ & 900 & 904 & 910 & 907.5 & 6.55 & 0.52 \\
\hline$\Sigma$ SFA & $54.0^{\mathrm{a}}$ & $50.5^{\mathrm{b}}$ & $49.9^{b}$ & $49.5^{b}$ & 0.87 & $<.0001$ \\
\hline $14: 0$ & $4.34^{\mathrm{a}}$ & $3.62^{b}$ & $3.28^{\mathrm{c}}$ & $3.30^{c}$ & 0.11 & $<.0001$ \\
\hline $16: 0$ & $28.7^{\mathrm{a}}$ & $23.7^{\mathrm{b}}$ & $23.3^{b}$ & $23.9^{b}$ & 0.27 & $<.0001$ \\
\hline 18:0 & $18.1^{b}$ & $20.8^{a}$ & $21.2^{\mathrm{a}}$ & $20.4^{\mathrm{a}}$ & 0.71 & 0.01 \\
\hline$\sum c-$ MUFA & 34.8 & 34.6 & 35.2 & 36.3 & 0.84 & 0.23 \\
\hline c9-14:1 & 1.03 & 0.98 & 0.83 & 0.87 & 0.07 & 0.06 \\
\hline c9-16:1 & $3.66^{a}$ & $3.33^{a}$ & $2.78^{b}$ & $2.75^{b}$ & 0.18 & $<.0001$ \\
\hline c9-18:1 & $27.6^{\mathrm{b}}$ & $27.5^{\mathrm{b}}$ & $29.0^{\mathrm{a}}$ & $30.2^{\mathrm{a}}$ & 0.64 & 0.001 \\
\hline$\sum n-3$ & $0.51^{a}$ & $0.37^{b}$ & $0.35^{\mathrm{b}}$ & $0.34^{b}$ & 0.01 & $<.0001$ \\
\hline $18: 3 n-3$ & $0.44^{\mathrm{a}}$ & $0.32^{b}$ & $0.31^{b}$ & $0.30^{b}$ & 0.01 & $<.0001$ \\
\hline $22: 5 n-3$ & $0.05^{\mathrm{a}}$ & $0.04^{b}$ & $0.04^{b}$ & $0.04^{b}$ & 0.01 & 0.001 \\
\hline$\sum n-6$ & $1.61^{\mathrm{b}}$ & $1.59^{b}$ & $1.71^{\mathrm{b}}$ & $2.20^{\mathrm{a}}$ & 0.05 & $<.0001$ \\
\hline $18: 2 n-6$ & $1.46^{\mathrm{c}}$ & $1.47^{\mathrm{c}}$ & $1.59^{b}$ & $2.04^{a}$ & 0.05 & $<.0001$ \\
\hline $20: 3 n-6$ & $0.08^{b}$ & $0.06^{\mathrm{c}}$ & $0.06^{\mathrm{c}}$ & $0.09^{a}$ & 0.01 & $<.0001$ \\
\hline$\sum$ PUFA & $2.11^{\mathrm{b}}$ & $1.96^{\mathrm{c}}$ & $2.06^{\mathrm{bc}}$ & $2.54^{\mathrm{a}}$ & 0.06 & $<.0001$ \\
\hline$\sum n-6: \sum n-3$ & $3.33^{c}$ & $4.33^{b}$ & $4.92^{b}$ & $6.44^{\mathrm{a}}$ & 0.67 & 0.04 \\
\hline$\sum$ PUFA : SFA & $0.04^{b}$ & $0.04^{b}$ & $0.04^{b}$ & $0.05^{a}$ & 0.01 & $<.0001$ \\
\hline
\end{tabular}

\footnotetext{
$\overline{\mathrm{a}, \mathrm{b}, \mathrm{c}}$ Means with different superscripts for a particular fatty acid profile are significantly different $(P<0.05)$; SEM: standard error of mean.

SS: sunflower seed; DDGS-15: 15\% wheat dried distillers' grain with solubles + sunflower seed; DDGS-30: $30 \%$ wheat dried distillers' grain with solubles + sunflower seed; F×D: fat depot by diet interaction; $c$ : cis; $t$ : trans; $\Sigma$ FA: total fatty acids in mg per $\mathrm{g}$ of tissue; $\Sigma$ PUFA: sum of polyunsaturated fatty acids $=\sum n-6+\sum n-3 ; \sum n-6$ : sum of 18:2n-6, 20:3n-6, 20:4n-6; $\sum n-3$ : sum of 18:3n-3, 20:5n-3, 22:5n-3; $\sum c$-MUFA: sum of c9-14:1, c7-16:1, c9-16:1, c11-16:1, c9-17:1, c9-18:1, c11-18:1, c12-18:1, c13-18:1, c14-18:1, c15-18:1, c9-20:1, c11-20:1; $\Sigma$ SFA: sum of 14:0, $15: 0,16: 0,17: 0,18: 0,19: 0,20: 0$.
}

Fat depot influenced the total FA content, with PRF having a higher $(P<0.05)$ content than SCF (Table 3). This could be linked to differences in water content between these fat depots, with SCF having higher water content than PRF (Anderson et al., 1972). Saturated FA (SFA) and cis-monounsaturated FA (c-MUFA) were the major families of FA of dietary or endogenous origin (Table 3). Fat depot influenced $(P<0.05)$ proportions of total SFA, with PRF having larger $(P<0.05)$ proportions than SCF. These dissimilarities could be linked to the proportions of 18:0, which exhibit a similar pattern. Generally, less mature fat depots situated externally, such as SCF, are less saturated than mature fat depots situated internally, such as PRF (Christie, 1978; Lee et al., 2011; Jiang et al., 2013). This is linked to a greater $\Delta-9$ desaturase activity index in external depots as opposed internal ones, and replacement of 18:0 with c9-18:1 in external fat depots. 
Fat depot had a significant effect on total and major C-MUFA, with SCF having larger $(P>0.05)$ proportions compared with PRF (Table 3 ). These findings agree with differences in $\Delta-9$ desaturase indices (Jiang et al., 2013) and mRNA abundance (Lee et al., 2011) reported previously. The proportions of 22:5n-3 and 20:4n-6 were the only $n-3$ and $n-6$ PUFA influenced by fat depot, with SCF having larger $(P<0.05)$ proportions of these FA compared with PRF (Table 3). However, these changes were small and did not alter the proportions of total $n-3$ and $n-6$ PUFA. Fat depot had no effect on total PUFA and $n-6: n-3$ ratio. For PUFA : SFA, the fat depot effect was significant, with SCF vs. PRF having a greater $(P<0.05)$ ratio (Table 3). Given that total PUFA was similar between the two fat depots, the higher PUFA : SFA reported for SCF could be related to the lower proportions of SFA reported for the SCF depot.

Table 3 Effect of fat depot on fatty acids (\% total fatty acids) of endogenous or dietary origin from steers fed red clover silage with sunflower seed and dried distillers' grains plus solubles

\begin{tabular}{|c|c|c|c|c|}
\hline & \multicolumn{2}{|c|}{ Fat depot } & \multirow{2}{*}{ SEM } & \multirow{2}{*}{$P$-value } \\
\hline & Subcutaneous fat & Perirenal fat & & \\
\hline$\sum F A(\mathrm{mg} / \mathrm{g})$ & $896^{\mathrm{b}}$ & $915^{\mathrm{a}}$ & 6.55 & 0.04 \\
\hline$\Sigma$ SFA & $42.4^{b}$ & $59.5^{\mathrm{a}}$ & 0.75 & $<.0001$ \\
\hline 14:0 & 3.68 & 3.56 & 0.08 & 0.38 \\
\hline $16: 0$ & 24.7 & 25.1 & 0.19 & 0.12 \\
\hline 18:0 & $12.1^{\mathrm{b}}$ & $28.2^{\mathrm{a}}$ & 0.59 & $<.0001$ \\
\hline$\sum c$-MUFA & $44.2^{\mathrm{a}}$ & $26.2^{b}$ & 0.70 & $<.0001$ \\
\hline$c 9-14: 1$ & $1.53^{\mathrm{a}}$ & $0.32^{b}$ & 0.05 & $<.0001$ \\
\hline$c 9-16: 1$ & $4.87^{\mathrm{a}}$ & $1.39^{b}$ & 0.15 & $<.0001$ \\
\hline c9-18:1 & $34.7^{\mathrm{a}}$ & $22.5^{\mathrm{b}}$ & 0.53 & $<.0001$ \\
\hline$\sum n-3$ & 0.39 & 0.38 & 0.01 & 0.22 \\
\hline $18: 3 n-3$ & 0.34 & 0.35 & 0.01 & 0.45 \\
\hline $22: 5 n-3$ & $0.05^{a}$ & $0.04^{b}$ & 0.01 & $<.0001$ \\
\hline$\sum n-6$ & 1.81 & 1.75 & 0.04 & 0.13 \\
\hline $18: 2 n-6$ & 1.65 & 1.62 & 0.04 & 0.41 \\
\hline $20: 3 n-6$ & $0.08^{a}$ & $0.06^{b}$ & 0.003 & 0.001 \\
\hline$\Sigma$ PUFA & 2.20 & 2.13 & 0.05 & 0.12 \\
\hline$\sum n-6: \sum n-3$ & 4.59 & 4.56 & 0.02 & 0.25 \\
\hline$\sum$ PUFA : SFA & $0.05^{\mathrm{a}}$ & $0.04^{\mathrm{b}}$ & 0.01 & $<.0001$ \\
\hline
\end{tabular}

$\overline{\mathrm{a}, \mathrm{b}, \mathrm{c}}$ Means with different superscripts for a particular fatty acid profile are significantly different $(P<0.05)$; SEM: standard error of mean.

c: cis; $t$ : trans; $\Sigma$ FA: total fatty acids in mg per $\mathrm{g}$ of tissue; $\Sigma$ PUFA: sum of polyunsaturated fatty acids: $\sum n-6+\sum n-3 ; \sum n-6$ : sum of 18:2n-6, 20:3n-6, 20:4n-6; $\sum n-3$ : sum of 18:3n-3, 20:5n-3, 22:5n-3; $\sum$ c-MUFA: sum of $c 9-14: 1, c 7-16: 1, c 9-16: 1, c 11-16: 1, c 9-17: 1, c 9-18: 1, c 11-18: 1, c 12-18: 1, c 13-18: 1, c 14-18: 1, c 15-18: 1, c 9-20: 1$, c11-20:1; $\Sigma$ SFA: sum of 14:0, 15:0, 16:0, 17:0, 18:0, 19:0, 20:0.

\section{Fatty acids of microbial origin}

Branched-chain FA (BCFA), trans-monounsaturated FA ( $t$-MUFA), CLA and non-conjugated 18:2 BHP (i.e. atypical dienes (AD)) were the major FA groups of microbial origin (Table 4; Fig 1A). Inclusion of SS in the diet led to reductions $(P<0.05)$ in the proportions of total and major BCFA. Proportions of these FA were further reduced $(P<0.05)$ by substitution with increasing levels of DDGS. Given that several BCFA in animal tissue are synthesised de novo by rumen microbes (Vlaeminck et al., 2006), it may be speculated that high levels of 18:2n-6 in SS and DDGS diets might have inhibited rumen microbes (Liu et al., 2011) leading to a decline in BCFA production. Differences in dietary protein content and interaction between dietary nutrients on rumen ecology and fermentation might also have played a role (Vlaeminck et al., 2006). Subsequent decreases when feeding DDGS could be due to reduced ruminal propionate (a precursor for BCFA biosynthesis) production from readily fermentable starch (Pethick et al., 2004). Total and major BCFA were 
affected $(P<0.05$; Table 4$)$ by fat depot and diet, but their interaction was not significant $(P>0.05)$. Perirenal fat as opposed to SCF had greater $(P<0.05)$ proportions of total BCFA and slightly lower $(P<0.05)$ proportions of anteiso-17:0. These findings could be linked to depot-specific differences in incorporation of individual FA (Hood et al., 1976).

Table 4 Effect of fat depot and diet on branched-chain fatty acid profiles (\% total FA) of beef steers

\begin{tabular}{|c|c|c|c|c|c|c|}
\hline \multirow{2}{*}{ Variable } & \multicolumn{4}{|c|}{ Diet } & \multirow{2}{*}{ SEM } & \multirow{2}{*}{$P$-value } \\
\hline & Control & ss & DDGS-15 & DDGS-30 & & \\
\hline$\sum$ BCFA & $3.15^{\mathrm{a}}$ & $2.36^{\mathrm{b}}$ & $2.23^{\mathrm{c}}$ & $1.95^{d}$ & 0.03 & $<.0001$ \\
\hline iso- $17: 0$ & $0.49^{\mathrm{a}}$ & $0.40^{\mathrm{b}}$ & $0.37^{c}$ & $0.33^{d}$ & 0.01 & $<.0001$ \\
\hline \multirow[t]{3}{*}{ anteiso-17:0 } & $0.81^{\mathrm{a}}$ & $0.57^{\mathrm{b}}$ & $0.57^{\mathrm{b}}$ & $0.52^{\mathrm{C}}$ & 0.01 & $<.0001$ \\
\hline & \multicolumn{4}{|c|}{ Fat depot } & & \\
\hline & \multicolumn{2}{|c|}{ Subcutaneous fat } & \multicolumn{2}{|c|}{ Perirenal fat } & & \\
\hline$\sum$ BCFA & \multicolumn{2}{|c|}{$2.36^{\mathrm{b}}$} & \multicolumn{2}{|c|}{$2.48^{\mathrm{a}}$} & 0.02 & 0.001 \\
\hline iso-17:0 & \multicolumn{2}{|c|}{0.40} & \multicolumn{2}{|c|}{0.40} & 0.01 & 0.57 \\
\hline anteiso-17:0 & \multicolumn{2}{|c|}{$0.63^{a}$} & \multicolumn{2}{|c|}{$0.61^{b}$} & 0.01 & 0.02 \\
\hline
\end{tabular}

${ }^{\mathrm{a}, \mathrm{b}, \mathrm{c}}$ Means with different superscripts for a particular fatty acid profile are significantly different $(P<0.05)$; SEM: standard error of mean; SS: sunflower seed; DDGS-15: 15\% wheat dried distillers' grain with solubles + sunflower seed; DDGS-30: 30\% wheat dried distillers' grain with solubles + sunflower seed; $\Sigma$ BCFA: branched chain fatty acids: sum of iso-15:0, anteiso-15:0, iso-16:0, iso-17:0, anteiso-17:0, iso-18:0.

The interaction between fat depot and diet was significant for total and major t-18:1 FA (Figure 1A). Perirenal fat as opposed to SCF had greater $(P<0.05)$ proportions of total and major $t$-18:1 FA including vaccenic acid (t11-18:1). These proportions were accentuated $(P<0.05)$ by feeding SS, maintained $(P>$ $0.05)$ by feeding DDGS-15, and attenuated $(P<0.05)$ by feeding the DDGS-30 diet. This could be the result of a combination of factors including lower $\Delta-9$ desaturase activity indices in PRF vs. SCF (Lee et al., 2011; Jiang et al., 2013), higher dietary 18:2n-6 observed for the diets containing SS, greater bypass of 18:2n-6 when feeding DDGS diets, and a decline in dietary fibre with increasing levels of DDGS, which might have reduced ruminal $\mathrm{pH}$ and negatively influenced biohydrogenation in the rumen (Hristov et al., 2005; Felix et al., 2012). It may also be due to greater de novo synthesis of FA in SCF and dilution of PUFA-BHP when DDGS were added to the diet.

Fat depot $\times$ diet interaction influenced $(P<0.05)$ the proportions of total CLA, $t 7, c 9-$ and $t 9, c 11-18: 2$ (Figure 1B). Overall, SCF had greater $(P<0.05)$ proportions of total CLA, $t 7, c 9-18: 2$, and $t 9, c 11-18: 2$ (rumenic acid), the major CLA isomer, and the proportions of these FA were increased $(P<0.05)$ by feeding SS and DDGS-15 diets $(P>0.05)$, but responses were somewhat diminished when feeding the DDGS-30 diet. Again, these findings could be ascribed largely to differences in $\Delta-9$ desaturase activity indices between PRF and SCF (Jiang et al., 2013), dissimilarities in dietary 18:2n-6 and ruminal pH related to the observed decline in dietary fibre with increasing DDGS.

Total $A D$ and $t 8, c 12-18: 2$, one of the major $A D$ isomers that is probably derived from $18: 2 n-6$, were affected by fat depot $\times$ diet interaction, with SCF having greater proportions than PRF. These AD proportions were increased $(P<0.05)$ by inclusion of $S S$, but further substitutions with DDGS led to no further changes $(P>0.05$; Figure 1C). These findings could reflect selective uptake or lower rate of metabolism of these AD in SCF (Kramer et al., 1998) and greater proportions of 18:2n-6 observed for the SS containing diets.

Fat depot and its interaction with diet had no $(P>0.05)$ effect on $t 11, c 15-18: 2$, one of the major AD isomers probably derived from 18:3n-3 (Figure 1C). Adding SS to the control diet had no $(P>0.05)$ effect on $t 11, c 15-18: 2$ either, but further substitutions with DDGS led to reductions $(P<0.05$; Figure $1 C)$. This may be related to dietary proportions of $n-3$ PUFA, which declined with the addition of SS and DDGS to the diet. During biohydrogenation, $18: 3 n-3$ is isomerized to CLA, which is hydrogenated to t11,c15-18:2 (Harfoot et al., 2007). 

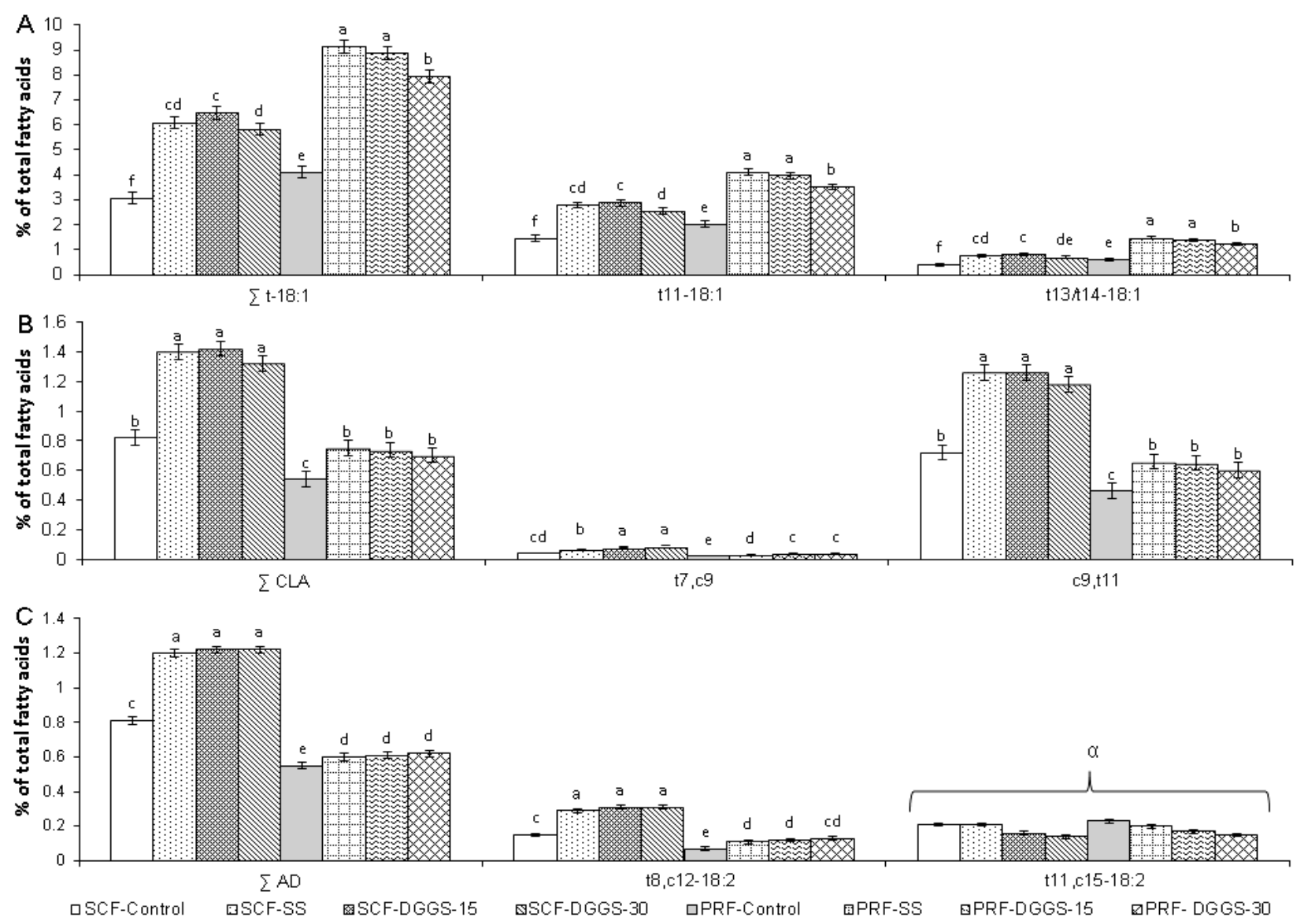

Fig 1 Effects of fat depot and diet on trans-18:1 isomers (A), CLAs (B) and atypical dienes (C) from beef steers.

Each bar represents mean \pm SEM.

${ }_{a, b, c}$ Means with different superscripts for a particular fatty acid profile are significantly different $(P<0.05)$; SEM: standard error of mean; SCF: subcutaneous fat; PRF: perirenal fat; SS: sunflower seed; DDGS-15: $15 \%$ wheat dried distillers' grain with solubles + sunflower seed; DDGS-30: 30\% wheat dried distillers' grain with solubles + sunflower seed; $\alpha$ : significant diet effect; $\Sigma \mathrm{AD}$ : atypical dienes: sum of $t 11, t 15-, c 9, t 13-/ t 8, c 12-, t 8, c 13-, c 9, t 12-/ c 16-18: 1, t 9, c 12-$, $t 11, c 15-, c 9, c 15-, c 12, c 15-18: 2$; $\Sigma$ CLA: conjugated linoleic acid = sum of t12,t14-, t11,t13-, t10,t12-, t9,t11-, t8,t10-, $t 7, t 9-$ $t 6, t 8-, c 9, t 11-, t 7, c 9-, t 11, c 13-, t 12, c 14-, c 11, t 13-, t 10, c 12-, \quad t 8, c 10-, t 9, c 11-; \sum t$-MUFA: sum of trans-monounsaturated fatty acids $=t 9-16: 1, t 6, t 7, t 8-, t 9-, t 10-, t 11-, t 12-, t 13 / t 14-, t 15-, t 16-18: 1$.

\section{Conclusions}

The remarkable differences between fat depots were related to the greater proportions of SFA and lower proportions of $c$-MUFA in PRF, as opposed to SCF. Feeding SS and DDGS-15 diets led to increases in proportions of vaccenic acid in PRF and rumenic acid in SCF, but feeding DDGS-30 was not so effective. Future strategies to enhance the composition of $t-18: 1$ and CLA in beef fat without compromising animal performance and meat quality may therefore include feeding SS and 15\% DDGS in forage-based diets and exploiting fat depot heterogeneity.

\section{Acknowledgements}

This research was funded by Alberta Meat and Livestock Agency (ALMA). C. Mapiye acknowledges the receipt of NSERC Fellowships funded through ALMA. P. Vahmani acknowledges his post-doctoral funding through the Agriculture and Agri-Food Peer Review Programme. Special thanks are extended to staff at Lacombe Research Centre (LRC) Beef Unit of AAFC for animal care, animal management and sample collection. The slaughter and processing of the cattle by the LRC abattoir staff are gratefully acknowledged.

\section{References}

Aldai, N., Dugan, M.E.R., Rolland, D.C. \& Kramer, J.K.G., 2009. Survey of the fatty acid composition of Canadian beef: Backfat and longissimus lumborum muscle. Can. J. Anim. Sci. 89, 315-329. 
Anderson, D.B., Kauffman, R.G. \& Kastenschmidt, L.L., 1972. Lipogenic enzyme activities and cellularity of porcine adipose tissue from various anatomical locations. J. Lipid Res. 13 (5), 593-599.

Brewer, M.S., 2012. Reducing the fat content in ground beef without sacrificing quality: A review. Meat Sci. 91, 385-395.

Christie, W.W., 1978. The composition, structure and function of lipids in the tissues of ruminant animals. Prog. Lipid Res. 17, 111-205.

Cruz-Hernandez, C., Deng, Z., Zhou, J., Hill, A.R., Yurawecz, M.P., Delmonte, P., Mossoba, M.M., Dugan, M.E.R. \& Kramer, J.K.G., 2004. Methods for analysis of conjugated linoleic acids and trans-18:1 isomers in dairy fats by using a combination of gas chromatography, silver-ion thin-layer chromatography/gas chromatography, and silver-ion liquid chromatography. J. AOAC Inter. 87, 545562.

Cruz-Hernandez, C., Kramer, J.K.G., Kennelly, J.J., Glimm, D.R., Sorensen, B.M., Okine, E.K., Goonewardene, L.A. \& Weselake, R.J., 2007. Evaluating the conjugated linoleic acid and trans 18:1 isomers in milk fat of dairy cows fed increasing amounts of sunflower oil and a constant level of fish oil. J. Dairy Sci. 90, 3786-3801.

Dilzer, A. \& Park, Y., 2012. Implication of conjugated linoleic acid (CLA) in human health. Crit. Rev. Food Sci. Nutr. 52, 488-513.

Felix, T.L., Zerby, H.N., Moeller, S.J. \& Loerch, S.C., 2012. Effects of increasing dried distillers grains with solubles on performance, carcass characteristics, and digestibility of feedlot lambs. J. Anim. Sci. 90, 1356-1363.

Field, C.J., Blewett, H.H., Proctor, S. \& Vine, D., 2009. Human health benefits of vaccenic acid. Appl. Physiol. Nutr. Metab. 34, 979-991.

Gómez-Cortés, P., Bach, A., Luna, P., Juárez, M. \& de la Fuente, M.A., 2009. Effects of extruded linseed supplementation on n-3 fatty acids and conjugated linoleic acid in milk and cheese from ewes. J. Dairy Sci. 92, 4122-4134.

Harfoot, C.G. \& Hazlewood, G.P., 2007. Lipid metabolism in the rumen. In: The Rumen Microbial Ecosystem. Eds: Hobson, P.N. \& Stewart, C.S., Academic and Professional, London, UK. pp. 382-426.

Hood, R.L. \& Thornton, R.F., 1976. Site variation in the deposition of linoleic acid in adipose tissue of cattle given formaldehyde-treated sunflower seed. Aust. J. Agric. Res. 27, 895-902.

Hristov, A.N., Kennington, L.R., McGuire, M.A. \& Hunt, C.W., 2005. Effect of diets containing linoleic acid- or oleic acid-rich oils on ruminal fermentation and nutrient digestibility, and performance and fatty acid composition of adipose and muscle tissues of finishing cattle. J. Anim. Sci. 83, 1312-1321.

Jiang, T., Mueller, C.J., Busboom, J.R., Nelson, M.L., O'Fallon, J. \& Tschida, G., 2013. Fatty acid composition of adipose tissue and muscle from Jersey steers was affected by finishing diet and tissue location. Meat Sci. 93, 153-161.

Johnson, G.H. \& Fritsche, K., 2012. Effect of dietary linoleic acid on markers of inflammation in healthy persons: A systematic review of randomized controlled trials. J. Acad. Nutr. Diet. 112, 10291041.e1015.

Kramer, J.K.G., Sehat, N., Dugan, M.E.R., Mossoba, M.M., Yurawecz, M.P., Roach, J.A.G., Eulitz, K., Aalhus, J.L., Schaefer, A.L. \& Ku, Y., 1998. Distributions of conjugated linoleic acid (CLA) isomers in tissue lipid classes of pigs fed a commercial CLA mixture determined by gas chromatography and silver ion-high-performance liquid chromatography. Lipids 33, 549-558.

Kramer, J.K.G., Hernandez, M., Cruz-Hernandez, C., Kraft, J. \& Dugan, M.E.R., 2008. Combining results of two GC separations partly achieves determination of all cis and trans 16:1, 18:1, 18:2 and 18:3 except CLA isomers of milk fat as demonstrated using ag-ion SPE fractionation. Lipids 43, 259-273.

Lee, J.H., Yamamoto, I., Jeong, J.S., Nade, T., Arai, T. \& Kimura, N., 2011. Relationship between adipose maturity and fatty acid composition in various adipose tissues of Japanese Black, Holstein and Crossbred (F1) steers. Anim. Sci. J. 82, 689-697.

Liu, S.J., Bu, D.P., Wang, J.Q., Sun, P., Wei, H.Y., Zhou, L.Y. \& Yu, Z.T., 2011. Effect of ruminal pulse dose of polyunsaturated fatty acids on ruminal microbial populations and duodenal flow and milk profiles of fatty acids. J. Dairy Sci. 94, 2977-2985.

Mapiye, C., Aldai, N., Turner, T.D., Aalhus, J.L., Rolland, D.C., Kramer, J.K.G. \& Dugan, M.E.R., 2012. The labile lipid fraction of meat: From perceived disease and waste to health and opportunity. Meat Sci. 92, 210-220.

Mapiye, C., Aalhus, J.L., Turner, T.D., Rolland, D.C., Basarab, J.A., Baron, V.S., McAllister, T.A., Block, H.C., Uttaro, B., Lopez-Campos, O., Proctor, S.D. \& Dugan, M.E.R., 2013a. Effects of feeding flaxseed or sunflower seed in high-forage diets on beef production, quality and fatty acid composition. Meat Sci. 95, 98-109. 
Mapiye, C., Turner, T.D., Rolland, D.C., Basarab, J.A., Baron, V.S., McAllister, T.A., Block, H.C., Uttaro, B., Aalhus, J.L. \& Dugan, M.E.R., 2013b. Adipose tissue and muscle fatty acid profiles of steers fed red clover silage with and without flaxseed. Livest. Sci. 151, 11-20.

Mapiye, C., Aalhus, J.L., Turner, T.D., Vahmani, P., Baron, V.S., McAllister, T.A., Block, H.C., Uttaro, B. \& Dugan, M.E.R., 2014a. Inclusion of sunflower seed and wheat dried distillers' grains with solubles in a red clover silage-based diet enhances steers performance, meat quality and fatty acid profiles. Anim. 8, 1999-2010.

Mapiye, C., Aalhus, J.L., Turner, T.D., Rolland, D.C., Basarab, J.A., Baron, V.S., McAllister, T.A., Block, H.C., Proctor, S.D. \& Dugan, M.E.R., 2014b. Types of oilseed and adipose tissue influence the composition and relationships of fatty acid biohydrogenation intermediate products in steers fed a grass hay diet. Lipids 49, 275-286.

Mapiye, C., Vahmani., P. Mlambo, V., Muchenje, V., Dzama, K., Hoffman, L.C. \& Dugan, M.E.R., 2015. The trans-octadecenoic fatty acid profile of beef: Implications for global food and nutrition security, Food Res. Int. 76, 992-1000.

Nakamura, M.T. \& Nara, T.Y., 2004. Structure, function, and dietary regulation of $\Delta 6, \Delta 5$, and $\Delta 9$ desaturases. Ann. Rev. Nutr. 24, 345-376.

Nantapo, C.W.T., Muchenje, V., Nkukwana, T.T., Hugo, A., Descalzo, A., Grigioni, G. \& Hoffman, L.C., 2015. Socio-economic dynamics and innovative technologies affecting health-related lipid content in diets: Implications on global food and nutrition security. Food Res. Int. 76, 896-905.

Pethick, D.W., Harper, G.S. \& Oddy, V.H., 2004. Growth, development and nutritional manipulation of marbling in cattle: A review. Aust. J. Exp. Agric. 44, 705-715.

Raes, K., De Smet, S. \& Demeyer, D., 2004. Effect of dietary fatty acids on incorporation of long chain polyunsaturated fatty acids and conjugated linoleic acid in lamb, beef and pork meat: A review. Anim. Feed Sci. Technol. 113, 199-221.

SAS, 2009. SAS for Windows, v. 9.3. In: SAS/STAT on-line user's guide: Statistics: SAS Institute, Inc., Cary, NC, USA.

Shingfield, K.J., Bonnet, M. \& Scollan, N.D., 2013. Recent developments in altering the fatty acid composition of ruminant-derived foods. Anim. 7 (Suppl. 1), 132-162.

Vahmani, P., Mapiye, C., Prieto, N., Rolland, D.C., McAllister, T.A., Aalhus, J.L. \& Dugan, M.E.R., 2015. The scope for manipulating the polyunsaturated fatty acid content of beef: A review. J. Anim Sci Biotechnol, 6:29 doi:10.1186/s40104-015-0026-z.

Vlaeminck, B., Fievez, V., Cabrita, A.R.J., Fonseca, A.J.M. \& Dewhurst, R.J., 2006. Factors affecting oddand branched-chain fatty acids in milk: A review. Anim. Feed Sci. Technol. 131, 389-417.

Webb, E.C., 2006. Manipulating beef quality through feeding. Appl. Anim. Husb. Rural Develop. 7, 5-15. 